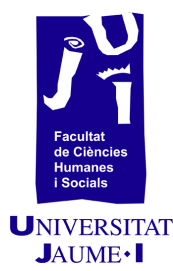

\title{
Sociedad moderna, sociedad deprimida: el fenómeno de la corrupción
}

Asier Hernández Blanco

al269405@uji.es / asier89hernandez@gmail.com 


\section{Resumen}

Este artículo se presenta como un análisis de los posibles tipos de corrupción existentes en la actualidad y sus campos de actuación. En él se ha pretendido conocer el alcance y los efectos que esta tiene en la sociedad, para lo que se ha utilizado un método críticodescriptivo. Cuatro han sido los objetivos a desarrollar durante la investigación. El primero consiste en hallar una definición al concepto de corrupción, que se acerque lo más posible a la realidad; en el segundo, se trata de diferenciar los diversos tipos de corrupción existentes en la actualidad; en el tercero, se desarrolla un breve estudio sobre los múltiples ámbitos de actuación de la corrupción, y, por último, se propone una serie de iniciativas para afrontar el fenómeno de la corrupción. Como fuentes principales para el apoyo de la investigación, son reseñables los estudios realizados por $\mathrm{M}$. Jiménez de Parga, N. López Calera, E. Garzón Valdés, J. F. Malem Seña, M. V. Caruso Fontán y S. A. Ribas Junior.

El primer paso del estudio ha consistido en el análisis del concepto desde diferentes perspectivas, para con ello hallar una definición lo más ajustada posible a la realidad, de forma que se evita la confusión de la terminología.

Posteriormente, a través del comentario de diversas teorías y la utilización de material jurídico, se diferencian algunos de los tipos de corrupción. Bajo las mismas fuentes, se analizan las diversas áreas en las que la corrupción puede hacer acto de presencia con el objetivo de formular una hipótesis, que pueda revelar cuáles son las causas y consecuencias que provoca la corrupción.

Por último, se propone una serie de reflexiones a modo de conclusión, con el objetivo de intentar hallar una respuesta, que pueda aclarar los motivos que causan la corrupción y con ello iniciar el camino a soluciones futuras posibles.

Palabras clave: corrupción, corrupción pública, corrupción privada.

\section{Introducción}

La corrupción es una enfermedad que ha aparecido sin excepción a lo largo de la historia en todo tipo de colectivos, modelos económicos y sistemas políticos, deteriorando el buen funcionamiento del Estado y de la sociedad. Así como la relación entre la ciudadanía y sus representantes. Ahora bien, sería un grave error focalizar la corrupción únicamente en la política, o culpar de 
ella a los actores políticos, puesto que la corrupción es un mal que afecta a toda la sociedad.

Si bien es cierto que en los últimos años la corrupción se ha convertido en uno de los mayores problemas de las sociedades contemporáneas $\mathrm{y}$ ha provocado un deterioro del sistema democrático debido a la institucionalización de esta, no se puede asegurar que el campo de la política sea el ámbito de mayor actuación de la corrupción, aún siendo evidente que es uno de los más afectados. En España, los datos relativos a la corrupción en el ámbito político son muy alarmantes, ya que en los últimos tres años la fiscalía ha procesado a 1378 personas por corrupción, entre los que se pueden mencionar los casos siguientes (abc.es, 2017):

El caso ERE o ERES de Andalucía, en el que se procesó a 26 personas entre las que se encontraban los expresidentes de la Junta de Andalucía Manuel Chaves y José Antonio Griñán, por la concesión de ayudas a empresas de forma irregular. Se trata de uno de los casos de corrupción más graves descubiertos hasta la fecha, pues se estima que la cifra defraudada está alrededor de los 855 millones de euros, de los cuales la Junta de Andalucía no ha recuperado ni un solo céntimo

La visita del Papa. El pasado 2016 la Audiencia Nacional procesó a 23 personas, debido a contrataciones irregulares llevadas a cabo durante la visita a la ciudad de Valencia en el año 2006 de su santidad, por aquel entonces, el papa Benedicto XVI. Entre los acusados que se sentaron en el banquillo se encontraban Pablo Crespo, empresario y expolítico del Partido Popular, encargado de financiación de varios eventos de su partido; Francisco Correa, supuesto cerebro de la trama Gürtel, y Juan Cotino, expresidente de las Cortes Valencianas.

El caso Nóos, uno de los procesos que más ha indignado a la sociedad española, por la posible vinculación de la Casa Real. Actualmente, ya ha sido visto para sentencia. En 2016 se inició una investigación en la que se vieron involucrados Iñaki Urdangarin y la infanta Cristina por irregularidades en las actividades del Instituto Nóos. El fallo del tribunal absolvió finalmente a la infanta, mientras que condenó a 17 personas involucradas en el caso, de entre ellas a Urdangarin, que fue condenado a seis años y tres meses de cárcel.

El caso de La Muela. En él fueron acusadas 40 personas entre las que se encontraba la exalcaldesa de la población María Victoria Pinilla, que fue condenada a 17 años de prisión, 78 de inhabilitación para el ejercicio de cargo público y al pago de varias multas que ascendieron a 9,95 millones de euros, por un total de catorce delitos de corrupción.

Caso de las tarjetas opacas de Caja Madrid, más conocido como «tarjetas black». En 2016 se llevó a cabo una investigación de las actividades realizadas por los exconsejeros $y$ exdirectivos del 
organismo por las que se demostró el desfalco de 15,5 millones de euros de manera irregular. Entre los acusados se encontraban personajes de la talla de Miguel Blesa o Rodrigo Rato.

Se puede comprobar que la corrupción afecta al mundo de la política en la actualidad independientemente del organismo o ámbito territorial. Es decir, no se debe caer en el error de pensar que la corrupción es inferior en el ámbito local o autonómico, y mayor a escala nacional, puesto que muchos de los casos son relativos a entidades e instituciones locales y autonómicas.

Como ya se ha mencionado, la corrupción es un problema que afecta a toda la sociedad, aún así, sorprende el poco interés de la ciudadanía por los asuntos políticos. Ello lo demuestra el último estudio realizado por el Centro de Investigaciones Sociológicas (CIS) en el año 2017, en el que se realizaron un total de 2487 entrevistas en 253 municipios y 49 provincias, a personas de ambos sexos mayores de 18 años. Los participantes de la encuesta respondieron a numerosas preguntas relacionadas con la economía y el funcionamiento de la política, dando su opinión personal y la visión global que tenían al respecto.

El presente estudio puede servir como punto de partida para hacerse una idea general del interés ciudadano respecto a la política en España, lo que se puede utilizar para llevar a cabo una reflexión crítica acerca de las causas de la corrupción y preguntarse si una de ellas puede ser una supuesta "apatía» por parte de la ciudadanía.

A continuación se muestra el balance de las respuestas relacionadas con la «situación política general en España» en octubre del año 2017 (CIS, 2017).

Tabla 1. Situación política general en España

\begin{tabular}{|c|c|}
\hline Calificación & Porcentaje de personas \\
\hline Muy mala & $43,7 \%$ \\
\hline Mala & $33,2 \%$ \\
\hline Regular & $17,9 \%$ \\
\hline Buena & $2,6 \%$ \\
\hline Muy Buena & $0,1 \%$ \\
\hline
\end{tabular}

Tabla de elaboración propia (Hernández-Blanco, 2017)

Se puede observar que el $76,9 \%$ de los encuestados calificaba negativamente el funcionamiento de la política, mientras que tan solo un $2,7 \%$ le otorgaba un resultado positivo. Esto indica que la satisfacción de la ciudadanía con sus representantes no es ni mucho menos buena. Los resultados no sorprenden, al tratarse de un 
período de crisis generalizada, en el que miles de personas perdieron su puesto de trabajo. El $28,3 \%$ de los encuestados considera la "corrupción y el fraude» entre los tres primeros problemas que tiene España actualmente (CIS, 2017).

Ahora bien, lo que sí sorprende son los datos que demuestran que aun estando descontentos con el funcionamiento político, la ciudadanía no tenía un especial interés en "la política», pues menos de la mitad de los encuestados la consideraron un asunto importante en su vida.

También resulta llamativo ver como la sociedad española no se interesa por la información relacionada con el funcionamiento de la Administración Pública, la política y, en general, del aparato del Estado. Un $23,7 \%$ de los encuestados raramente habla con amigos sobre política, y un $20,8 \%$ afirmó que no lo hacía nunca. Datos similares se muestran al preguntar sobre conversaciones 0 discusiones con la familia, o con compañeros de trabajo o estudio. El $24,6 \%$ lo hace rara vez con la familia y el $13,6 \%$ con los amigos; mientras que el $19,3 \%$ afirma no hacerlo nunca con la familia, y el $14,4 \%$ con los compañeros. Más relevantes aún son los datos que muestran que el $38,5 \%$ de los encuestados no lee nunca noticias sobre política, el $32,6 \%$ no las escucha o las ve, y el $46,6 \%$ no busca ningún tipo de noticia política en internet (CIS, 2017). Por lo tanto, se puede observar como una parte de la sociedad se desentiende del panorama político.

Tabla 2. Hablar o discutir sobre asuntos relacionados con la política en general

\begin{tabular}{|c|c|c|}
\hline & Raramente & Nunca \\
\hline Con amigos & $23,7 \%$ & $20,8 \%$ \\
\hline Con la familia & $24,6 \%$ & $19,3 \%$ \\
\hline Con compañeros & $13,6 \%$ & $14,4 \%$ \\
\hline
\end{tabular}

Tabla de elaboración propia (Hernández-Blanco, 2017)

Tabla 3. Leer, escuchar, ver o buscar noticias relacionadas con la política en general

\begin{tabular}{|c|c|}
\hline & Nunca \\
\hline Leer & $38,5 \%$ \\
\hline Escuchar o ver & $32,6 \%$ \\
\hline Buscar en internet & $46,6 \%$ \\
\hline
\end{tabular}


Tabla de elaboración propia (Hernández-Blanco, 2017)

Respecto a las preguntas relacionadas con la insatisfacción política y, en consecuencia, el descontento social, los encuestados situaron «los/as políticos/as en general, los partidos y la política» en tercer lugar, y «la corrupción y el fraude» en el cuarto (CIS, 2017).

También es destacable que el paro y los problemas económicos se sitúan a la cabeza de las preocupaciones de los españoles. Por lo tanto, y como primera conclusión, se puede deducir que, en base a las estadísticas, los ciudadanos y ciudadanas españoles tienen un descontento generalizado hacia el funcionamiento de la política debido a la pérdida de empleo provocado por la crisis económica, pero no por la corrupción o el fraude. El descontento queda patente: el $51,8 \%$ de los encuestados no votaría jamás al Partido Popular, si las elecciones se realizasen al día siguiente de la realización de la encuesta. Y un $11,8 \%$ de ellos no acudiría a votar.

De acuerdo con los datos extraídos se puede decir que la corrupción se toma como algo natural en la política española. La ciudadanía sabe de su existencia pero se preocupa relativamente poco por ella, ya que toma como problemas de mayor importancia los de índole económica relacionados con el paro (CIS, 2017).

El mal endémico de la corrupción está instaurado en lo más profundo de la sociedad. ¿Quizás debido a la inactividad de la ciudadanía? ¿A la pasividad de los partidos políticos? ¿A la falta de imparcialidad por parte del sistema judicial? O ¿debido a las tramas de corrupción, que se han extendido por todo el aparato del Estado de forma que se hace muy difícil el buen funcionamiento de la democracia? Todas estas preguntas son fundamentales para encontrar una solución posible a las causas de la corrupción.

\section{Objetivos}

En este artículo se desarrollan cuatro objetivos:

1. Proponer una definición del concepto de corrupción, la cual se adecue al momento actual.

2. Diferenciar los tipos de corrupción existentes en España en la actualidad, en base a diferentes clasificaciones.

3. Delimitar los diversos ámbitos de actuación de la corrupción.

4. Reflexionar sobre algunas de las medidas posibles para afrontar las causas de este fenómeno.

\section{Resultados}

De acuerdo con la reflexión crítica, se comprueba que son múltiples los motivos por los que surge la corrupción. Aun así, se debe recordar que estos diversos factores se deben analizar desde la 
perspectiva de la cultura dominante en una sociedad determinada, pues de lo contrario se puede caer en el error de considerar como corrupción algo cuando quizá no lo es, simplemente porque se toma como referencia la cultura propia. También se observa que hay diferentes teorías que atribuyen la corrupción al funcionamiento del mercado, del sistema, etc., y autores que, por su parte, piensan que el problema es más profundo que la mera articulación de un sistema político. Posiblemente, todos abarquen su parte de razón y ninguno tenga la verdad absoluta, pues esta siempre es relativa. Por ello mismo se debe ir con cuidada claridad y extrema precaución cuando se habla de dichos motivos, puesto que es fácil caer en la generalización y con ello dar rienda suelta a opiniones confusas al respecto.

Es una evidencia que la generalización de un hecho no incluye a toda la sociedad, puesto que en el momento en que haya un solo individuo que no cumpla la regla general, se tendrá que hablar de una excepción, y por lo tanto se rompe dicha generalidad. Ahora bien, para hablar de términos tan complejos como el de corrupción, es necesario generalizar para poder explicar una acción corrupta, pero siempre dejando claro que la corrupción es la excepción y no la generalidad.

Que la corrupción ha existido en todos los sistemas políticos, en mayor o menor expresión, desde que la política es política, es una realidad. Independientemente de la época, el ser humano ha buscado sacar un beneficio extraposicional a la función derivada de rol social o posicional, puesto que este ha sido, es y será susceptible de corromperse (Bilbao Alberdi, 2014; Garzón Valdés, 1997). Si el ser humano es susceptible de corrupción todo sistema político también lo es. Por lo tanto se debe descartar la posibilidad de que algún régimen sea el originario de la corrupción, como podría haberse pensado en el caso de la dictadura. Hay autores que aseguran que la dictadura no es el origen de la corrupción, pero sí que sobrevive y se alimenta de ella. Cierto es que a mayor clandestinidad y oscurantismo, mayor posibilidad de corrupción (Soriano, 2011). Y en una dictadura, la publicidad -haciendo referencia al acceso libre de documentos- brilla por su ausencia.

Por su parte, las ciencias económicas afirman que los orígenes de la corrupción están basados en el mercado y en su funcionamiento ineficaz, puesto que los múltiples impedimentos, trabas e inconvenientes que generan, supuestamente, los Estados a la hora de comerciar son los verdaderos culpables de la corrupción. Se habla de burocracia excesiva, control de precios, monopolio o discrecionalidad como posibles factores que den origen a la corrupción. Todos ellos tienen su parte de explicación, pues varios de los autores anteriormente mencionados constatan la excesiva 
burocracia como germen de la corrupción, así como la discrecionalidad del funcionariado público.

Una burocracia excesiva ralentiza el funcionamiento de la Administración y, en consecuencia, se ven afectados todos aquellos que interactúan con ella, ya sean particulares o empresas. Un claro ejemplo de ello en España, fuera del marco económico, son las listas de espera en los hospitales para tener atención especializada. Se puede acusar a la saturación del sistema público de salud o a la falta de personal, pero lo cierto es que el proceso burocrático también afecta al procedimiento $y$, el que tiene posibilidad de ello, recurre a la Vitamin $B$ o "enchufismo» para intentar ser atendido lo antes posible. ¿Las personas que utilizan su posición social, es decir, tener algún tipo de relación con un miembro del hospital para conseguir una cita lo antes posible están realizando un acto de corrupción? Legalmente se puede asegurar que no, pues solo los delitos tipificados como tales en el Código Penal se pueden considerar «corrupción»y, por tanto, penarse por la ley. Ahora bien, eso no significa que la moral no pueda reprobar dicha acción y calificarla de incorrecta.

Por su parte, también es cierto que la discrecionalidad en ciertos puestos o cargos de la Administración puede favorecer a la corrupción, es decir, la no publicidad o acceso libre a una información, puede favorecer que detrás de ella se oculten casos de corrupción. Ahora bien, ¿̇la supuesta ineficacia de un sistema puede «justificar» la corrupción? Cuando digo justificar, me refiero a si realmente esta puede ser la verdadera causa de dicho fenómeno. Si la respuesta fuese afirmativa, entonces bastaría con mejorar el sistema, y la corrupción disminuiría o terminaría por desaparecer. Pero no creo que la respuesta sea tan obvia, porque entonces se estaría hablando de "nadie se ha dado cuenta» o "nadie quiere cambiarlo». Por una parte, soy de la opinión de que el sistema democrático funciona como una maquinaria estatal enorme, porque se deben señalar en las leyes todas las normas y reglas que la ciudadanía debe seguir y respetar. ¿Esto por qué es así? Por la mera naturaleza del ser humano. Y aún así, todavía hay quien se las arregla para conseguir sacar beneficios llevando a cabo actos ilegales. Por otro lado, creo que la confidencialidad y discrecionalidad de ciertos cargos de la Administración son necesarios, pues el ciudadano no debe conocerlo todo, ya que la sociedad no está preparada para saber todo lo que quizá sí debiese saber.

Leídas estas líneas creo que está bastante claro dónde quiero llegar. La educación del ser humano es la base fundamental del buen criterio personal, del desarrollo individual y colectivo, y del buen funcionamiento de un sistema político. Si no se invierte en educación, porque el sistema está corrompido $y$, por lo tanto, las partidas presupuestarias destinadas para ello se desvían a bolsillos 
privados, las personas del futuro no estarán lo suficientemente formadas como para tener una mayor amplitud en su campo de visión, y así seguirán los pasos de los hasta ahora dirigentes del sistema. No hay que fantasear pensando que se está hablando de magnates corruptos, que influencian en los partidos políticos, para que las sociedades no se desarrollen y no puedan alcanzar la plenitud para la mayoría de sus ciudadanos. Sino a personas normales que viven en cualquier barrio y actúan como creen que se debe actuar, es decir, que hacen lo que se les ha enseñado. Pues el cabeza de familia no es la persona que se sienta en el Congreso de los Diputados, sino el padre y la madre que enseñan a sus hijos a comportarse en las diferentes situaciones que les depara la vida.

Cuando se afirma que la educación es la base para el futuro, se quiere decir que es la única manera en la que las personas pueden desarrollar un pensamiento crítico hacia lo que está ocurriendo e intentar cambiarlo. Muchas veces -o yo quiero pensar que en la mayoría de ellas-, los errores que se comenten en el ámbito político no son intencionados. Es decir, considero la corrupción como un mal aislado y no como un problema universal que afecta a todas las capas de la sociedad. Pero sí creo que debe cambiarse la moral social, pues aún a día de hoy se cometen actos que pueden ir más allá de la legalidad o que son moralmente reprobables, porque siempre se han hecho así, porque no se tiene conciencia de ello o porque se toma al sistema público como enemigo. Se pueden citar varios ejemplos al respecto, como el cobro de la prestación por desempleo mientras se trabaja en el extranjero o en economía sumergida, fingir una lesión para cobrar la baja laboral, estafar a la Administración para recibir una subvención, etc. Todos ellos no son fantasías, son situaciones cotidianas que se dan y se han dado en España. Si no fuese así, ¿por qué iban a existir leyes que lo regulasen? Por lo tanto el problema de la corrupción va más allá del mero funcionamiento del sistema democrático.

Bajo mi punto de vista una clave para mejorar la lucha anticorrupción sería reflexionar acerca del origen, o mejor dicho, de los orígenes de la corrupción y si esta podría tener sus principios en el sistema moral establecido al que Soriano llama "orden social». La falta de compromiso con la sociedad hace que el funcionamiento del sistema se deteriore. Anteriormente he mencionado la educación como factor ineludible para la mejora de dicho orden social, pero como dice Ribas (2013) la corrupción se convierte en un círculo vicioso, del cual es muy difícil salir. La educación es una de las posibles soluciones a la mejoría del sistema social, y por lo tanto a la corrupción. Sin embargo, la corrupción ha hecho que no se invierta en educación; por lo tanto, las personas siguen cometiendo los mismos vicios que antaño y sigue habiendo corrupción, a lo sumo aumenta. 
Una última aclaración: en ningún caso se está juzgando la labor del profesorado de escuela, de educación superior, etc., impartida en España, o una mala educación por parte de los padres hacia sus hijos. Simplemente se ha llevado a cabo una reflexión crítica, en la cual puede que ciertos patrones de conducta -los cuales se propone que deberían ser reeducados en la sociedad- pueden ser uno de los orígenes de la corrupción. Por eso es más que necesario repensarlos y con ello evolucionar como comunidad, evitar cometer errores de antaño y sembrar nuevos.

\section{Discusión y conclusiones}

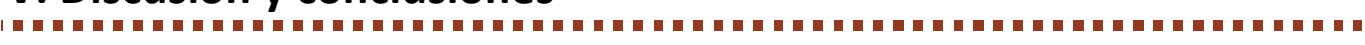

Abarcar en toda su extensión el fenómeno de la corrupción presenta un verdadero reto al tratarse de un concepto que alberga numerosas posibilidades. Ahora bien, la verdadera problemática que presenta la definición del concepto hoy en día es saber exactamente qué tipo de actos se pueden considerar corrupción y cuáles no. De ahí se extrae la importancia de acotar bien dicha definición, puesto que debido a la ambigüedad del lenguaje, se podría utilizar de manera arbitraria para juzgar un comportamiento, que bajo ningún concepto se podría considerar corrupto.

Los Estados encontraron la fórmula de definir la corrupción a través de los textos legales y condenarla por medio de las leyes. Ahora bien, eso no ha significado en ningún caso que sean las medidas más adecuadas para terminar con la corrupción, pues aún habiendo numerosas sanciones al respecto -en España todas ellas reguladas por la Ley Orgánica 10/1995, de 23 de noviembre, del Código Penal-, el fenómeno de la corrupción es uno de los problemas principales de las democracias modernas. Eso significa que las causas de la corrupción no van ligadas al tipo de régimen de los países, sino que viene provocada por algo más; posiblemente por un rasgo inherente al ser humano, que puede desarrollarse fácilmente en la persona si esta no recibe una educación adecuada. Por supuesto, no se puede negar que en regímenes autoritarios las corruptelas alcanzan límites muy elevados, pero eso no da pie a concluir que son el origen de la corrupción.

Por ello se buscó otro origen al problema, y se le otorgó la autoría al funcionamiento del aparato del Estado. Es decir, a su funcionamiento burocrático complejo, a la discrecionalidad de su funcionariado, a la exclusividad administrativa, etc., lo que es realmente cierto y que, por lo tanto, se debería solucionar. Pero aun siendo uno de los principales problemas del origen de la corrupción, la solución no traería consigo la erradicación de las tramas corruptas, pues estas no son provocadas por el propio sistema, sino que las personas que interaccionan con el sistema son las que las llevan a cabo; son las personas las que se corrompen, no el sistema. El 
sistema democrático no está corrompido, sino los actores que interactúan a través de él para sacar beneficios no justificables utilizando su rol social o posicional, en detrimento del resto de los ciudadanos y ciudadanas.

Pero el problema es más grave de lo simplemente aparente. Podría tratarse de un problema de fondo basado en una educación debilitada por el abandono de los valores fundamentales, los cuales son la base para formar una moral cívica fuerte capaz de superar los deseos propios en beneficio del conjunto de la sociedad. Son el egoísmo, la avaricia, el desinterés, etc. los que pueden haber provocado la apatía de una sociedad, que cada día cuenta con menos mecanismos de defensa contra la corrupción; pero no porque no se disponga de ellos, sino porque ese supuesto desinterés generalizado por el «bien común» puede haber desembocado en un individualismo que haya llevado a la sociedad a resquebrajarse en pequeños círculos en los que solamente importa el beneficio propio.

Sería desde esta perspectiva desde donde habría que atajar el problema de la corrupción, pues las leyes se convierten en ineficaces cuando las personas que deben velar por ellas se corrompen. Sin embargo, se convierten en inocuas cuando la responsabilidad de aquellos y aquellas que tienen la capacidad de cambiar la sociedad se transforma en irresponsabilidad; cuando aquellos y aquellas que deben luchar por construir una democracia mejor simplemente se adaptan a los cambios sin más por falta de un pensamiento crítico que analice las diferentes posibilidades que brinda el sistema.

Quizás la verdadera solución a la corrupción no pase únicamente por la publicación de nuevas leyes o por una reforma en el funcionamiento del sistema, sino más bien por el compromiso social del individuo para con los demás, por la búsqueda de un bienestar social a través del conjunto de la sociedad.

Bajo esta afirmación se puede argumentar la reflexión siguiente: son los valores y el desarrollo individual los que llevan a cambiar la sociedad. Por lo tanto, debe haber una introspección, pues quizá la solución esté en los propios individuos. Tener una escala de valores y no traicionarlos bajo ningún concepto trae consigo el desarrollo moral individual y en él se basa el compromiso para con los demás.

\section{Bibliografía}

Abc. 2017. "Los principales casos de corrupción en España». $A B C$. Acceso del 3 de julio de 2017. https://www.abc.es/espana/abciprincipales-casos-corrupcion-espana201701130332_noticia.html.

Caruso Fontán, María Viviana. 2009. «El concepto de corrupción. Su evolución hacia un nuevo delito de fraude en el deporte como 
forma de corrupción en el sector privado». Foro: Revista de ciencias jurídicas y sociales 9: 145-172.

CIS. 2017. "Barómetro de octubre de 2017». Centro de Investigaciones Sociológicas. Acceso del 10 de septiembre de 2017

http://www.cis.es/cis/opencm/ES/1_encuestas/estudios/ver.jsp ?estudio=14364.

Garzón Valdés, Ernesto. 1997. «Acerca del concepto de corrupción». En La corrupción política, editado por Francisco J. Laporta y Silviana Álvarez, 39-70. Madrid: Alianza.

Jiménez de Parga, Manuel. 1997. "La corrupción en la democracia». En La corrupción política, editado por Francisco J. Laporta y Silviana Álvarez, 135-156. Madrid: Alianza.

Ley Orgánica 10/1995, de 23 de noviembre, del Código Penal. Madrid.

Ley Orgánica 8/2007, de 4 de julio, sobre financiación de los partidos políticos. Madrid.

López Calera, Nicolás María. 1997. «Corrupción, ética y democracia: nueve tesis sobre la corrupción política». En La corrupción política, editado por Francisco J. Laporta y Silviana Álvarez, 117135. Madrid: Alianza.

Malem Seña, Jorge F. 1997. «El fenómeno de la corrupción». En La corrupción política, editado por Francisco J. Laporta y Silviana Álvarez, 71-90. Madrid: Alianza.

Ribas Junior, Salomão Antônio. 2013. Corrupción pública y privada. Cuatro aspectos: ética en el servicio público, contratos, financiación electoral y control. Salamanca: Universidad de Salamanca.

Rose-Ackerman, Susan. 1996. "The Political Economy of CorruptionCauses and Consequences». The World Bank, 74. Acceso del 2 de julio de 2017. http://documents.worldbank.org/curated/en/231001468762302 694/The-political-economy-of-corruption-causes-andconsequences.

-. 2006. International Handbook on the Economics of Corruption. Londres: Elgar.

Soriano, Ramón. 2011. "La corrupción política: tipos, causas y remedios». En Calidad democrática e instituciones políticas, editado por Ramón Soriano y Gloria Trocello, 39-65. Sevilla: Aconcagua. 
Viaña Remis, Enrique. 2006. «El mercado de la corrupción». En Fraude y corrupción en el Derecho penal económico europeo: eurodelitos de corrupción y fraude, editado por Luis Arroyo Zapatero y Adán Nieto Marín, 485-500. Cuenca: Universidad de Castilla-La Mancha.

Villoria Mendieta, Manuel. 2014. «Corrupción pública». Eunomía. Revista en Cultura de la Legalidad 5: 159-167.

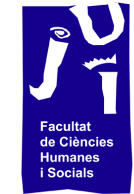

UNIVERSITAT JAUME $\cdot \mathbf{I}$

Warren, Mark E. 2005. «La democracia contra la corrupción». Revista mexicana de ciencias políticas y sociales 193: 109-141. 